Article

\title{
Preparation and Performance of a Waterborne UV/Al Low Infrared Emissivity Coating
}

\author{
Xiaoxing Yan ${ }^{1,2, *}$ and Lin Wang ${ }^{2}$ \\ 1 Co-Innovation Center of Efficient Processing and Utilization of Forest Resources, \\ Nanjing Forestry University, Nanjing 210037, China \\ 2 College of Furnishings and Industrial Design, Nanjing Forestry University, Nanjing 210037, China; \\ wanglin@njfu.edu.cn \\ * Correspondence: yanxiaoxing@nuaa.edu.cn; Tel.: +86-25-8542-7528
}

Received: 24 August 2020; Accepted: 14 September 2020; Published: 15 September 2020

\begin{abstract}
An Al powder filler, nano silica slurry and KH560 were mixed with a prepared waterborne UV-curable coating, and the coating was optimized by an orthogonal experiment. Influences of the $\mathrm{Al}$ powder concentration on the gloss, infrared emissivity, brightness, mechanical properties, corrosion resistance and other related properties of the coating were further discussed. The results show that the influence of the Al powder concentration on the gloss was more significant, followed by the UV curing time and nano silica slurry concentration. After studying the key role of the concentration of the Al powder, we found that as the concentration of the Al powder is augmented from $10.0 \%$ to $25.0 \%$, the gloss lessened from $19.1 \%$ to $8.5 \%$. As the concentration of the Al powder was augmented from $10.0 \%$ to $40.0 \%$, the infrared emissivity lessened from 0.649 to 0.083 and the brightness L' value of the coating was step-by-step augmented and inclined to be stable; in addition, the coating's mechanical properties reached an excellent level. The coating containing 25.0\% Al powder had the best corrosion resistance, surface morphology and comprehensive properties, which can potentially be used for infrared stealth technology.
\end{abstract}

Keywords: waterborne UV-curable coating; Al powder concentration; infrared emissivity; gloss; coating properties

\section{Introduction}

Infrared low emissivity coatings can not only benefit infrared stealth militarily, but also reduce the harm of infrared light to the human body in daily life by virtue of its ability to reflect more and absorb less infrared light [1]. As a special functional coating, it is widely used in military investigation and other aspects [2]. Lv et al. [3] fabricated a polydimethylsiloxane (PDMS)-modified polyurethane (PU)/Ag composite coating with super-hydrophobicity and low infrared emissivity via the glass rod scraping method. The results indicated that at the $10 \mu \mathrm{m}$ particle size of flaky Ag powder and a $50 \%$ concentration of Ag powder in the coating, the coating had a dense surface structure and the lowest infrared emissivity. He et al. [4] fabricated a low infrared emissivity coating using graphene surface-modified flaky aluminum complex powders (rGO-FAl) as fillers. Compared with pure flaky aluminum, the Vis-NIR diffuse reflectance of the rGO-FAl complex powders was significantly decreased, which was good for the low gloss of the coating. In addition, the coating maintained low infrared emissivity. Voti et al. [5] designed and simulated $\mathrm{VO}_{2} /$ metal multilayers to obtain a large tunability of the thermal emissivity of the infrared (IR) filters in the typical mid wave IR window of many infrared cameras. The multilayer structure was optimized to realize a low emissivity filter at high temperatures, useful for military purposes. 
With strict national control of the environmental protection industry, waterborne coatings have been vigorously promoted [6,7]. Among them, waterborne UV-curable coatings have gradually become the research hotspot of domestic and foreign scholars due to their advantages of easy adjustment of concentration, fast drying speed [8], harmless volatiles and wide application range [9]. However, at the same time, it also has the disadvantages of poor corrosion resistance [10] and high gloss [11], which is less propitious regarding compatibility with visible light, thus limiting its domain in infrared low-emission materials. Therefore, an effective solution for achieving compatibility between low infrared emissivity and visible light is the only way to expand the application field of waterborne UV coatings.

Currently, most of the infrared low emissivity coatings are produced by giving the metal a strong infrared reflection ability, via a filler added into the coating [12]. For instance, Qi et al. [13] prepared low infrared emissivity coatings with outstanding thermal stability utilizing silicone resin as a binder, flake $\mathrm{Al}$ powder as a pigment and a low-melting glass powder as a functional filler. The results investigated that the low emissivity coating displayed favorable thermal stability at a $1.5 \mathrm{Al} /$ polysiloxane ratio and the coating infrared emissivity was about 0.25 at $600{ }^{\circ} \mathrm{C}$, which can show a good application prospect. Zhang et al. [14] prepared a polydimethylsiloxane (PDMS)-modified polyurethane (PU)/Al composite paint coat with super-hydrophobicity and low infrared emissivity. Research suggested that the paint coat possessed the lowest infrared emissivity and gloss performances at an $80^{\circ} \mathrm{C}$ curing temperature. Hu et al. [15] made low infrared emissivity paint coats owning excellent heat resistance, choosing epoxy-siloxane and $\mathrm{Al}$ as the binder together with pigment. Detailed conclusions indicated that the cured composite paint coats still possess low emissivity, profitable heat ageing and anti-thermal shock after the stability test. From the above research, we see that the metal Al powder stands out among numerous metal fillers on account of its low-cost, accessibility and satisfactory manifestation. However, these studies are based on silicone resin, polydimethylsiloxane-modified polyurethane, and epoxy-siloxane, but less based on waterborne UV coatings.

In a preliminary study [16], the influence of infrared emissivity, chromaticity distortion and corrosion resistance of $\mathrm{Al} /$ waterborne acrylic coatings were investigated. For infrared emissivity coatings, the drying speed of the waterborne coatings is relatively slow [17], while the waterborne UV-curable coatings prepared in this paper are environmentally friendly and fast in drying. Waterborne UV-curable coatings not only eliminate volatile organic compounds (VOC) pollution, but also have the characteristics of rapid curing and energy saving.

As a crosslinking agent, a silane coupling agent can promote the interface combination between a coating and resin and improve the corrosion resistance of the coating [18]. In addition, a nano silica slurry can effectively reduce the coating gloss [19]. In this paper, an orthogonal experiment was utilized to optimize the process parameters, in order to obtain the waterborne UV coating possessing a low infrared emissivity, low gloss, low brightness as well as favorable corrosion resistance and mechanical properties. We also probe the influence of the $\mathrm{Al}$ powder concentration on the coating, so as to lay the foundation for the technical production of UV-curable, infrared and low emissivity coatings.

\section{Materials and Methods}

\subsection{Experimental Materials}

Isophorone diisocyanate (IPDI, resin, $\mathrm{M}_{\mathrm{w}}: 222.28 \mathrm{~g} / \mathrm{mol}$, CAS No.: 4098-7-19), polyether diols (PED, resin, $\mathrm{M}_{\mathrm{w}}: 2000 \mathrm{~g} / \mathrm{mol}$, CAS No.: 25322-69-4), hydroxyethyl methacrylate (HM, resin, $\mathrm{M}_{\mathrm{w}}$ : 130.14, CAS No.: 868-77-9), 2,2-dihydroxymethylpropionic acid (DMPA, Chain extender, $\mathrm{M}_{\mathrm{W}}$ : $134.13 \mathrm{~g} / \mathrm{mol}$, CAS No.: 4767-03-7), tripropylene glycol diacrylate (TGD, Active diluent, $\mathrm{M}_{\mathrm{W}}$ : $300.35 \mathrm{~g} / \mathrm{mol}$, CAS No.: 42978-66-5) and 2,4,6-trimethylbenzoyl-diphenylphosphine oxide (TBDPO, Photoinitiator, $\mathrm{M}_{\mathrm{w}}$ : $348.4 \mathrm{~g} / \mathrm{mol}$, CAS No.: 75980-60-8) were offered by Linyi Dongyi Chemical Co., Ltd., Shandong, China. Filler: Al powder 4017 (piece diameter: $10 \mu \mathrm{m}$, thickness: $220 \mathrm{~nm}$, solid concentration: $65.0 \%, 65.0 \% \mathrm{Al}$ powder mixed with $35.0 \%$ oleic acid) was offered by Xuhui New Material Technology Co., Ltd., Shandong, China. Dispersant: KH560 was offered by 
Zhongjie Chemical Technology Co., Ltd., Guangzhou, China. Other auxiliary materials: nano silica slurry (particle size: $150 \mathrm{~nm}$, solid concentration: 15.0\%) was offered by Nanjing Tianxing New Material Co., Ltd., Jiangsu, China. Anhydrous ethanol was offered by Zhongi Chemical Co., Ltd., Shandong, China. Al substrate $(100 \mathrm{~mm} \times 50 \mathrm{~mm} \times 1 \mathrm{~mm})$ was provided by Wuxi Dongyue metal material Co., Ltd. All reagents were pure without further treatment.

\subsection{Preparation of Coatings}

The compositions are based on mass/mass \% values. The pre weighed IPDI, HM, DMPA, TGD and TBDPO were mixed with PED, and then added into a four-neck flask with a condensator, mixer and thermometer for mixing. The rotating speed of this system was set to $100 \mathrm{r} / \mathrm{min}$, and it reacted at $75^{\circ} \mathrm{C}$ for $4 \mathrm{~h}$, and afterwards the temperature at a slow speed fell to room temperature to acquire the waterborne UV-curable coating. The $\mathrm{pH}$ value and solid concentration of the waterborne UV-curable coating were approximately 7.0 and $26.5 \%$, respectively. Among them, the IPDI concentration was $35.0 \%$, PED concentration was $15.2 \%$, DPA concentration was $5.8 \%$, HM concentration was $30.0 \%$, TGD concentration was $10.0 \%$ and TBDPO concentration was $4.0 \%$. TBDPO in waterborne UV-curable coatings can generate active radicals or cations afterwards, absorbing the high-intensity UV light produced by the Fumax 650 UV curing apparatus (Kunshan Honest Electronic Technology Co., Ltd., Kunshan, China), which can stimulate polymerization, cross-linking and a graft reaction, causing the coating to cure at a certain time.

An orthogonal experiment is a method to study multi factors and multi levels. It selects some representative points from the overall test according to the orthogonality. These representative points have the characteristics of uniform dispersion, integrity, and comparability. Orthogonal experimental design is the main method of fractional factorial design, and is a high-efficiency, fast and economic experimental design method. Table 1 showed the configuration information of the experimental samples, among which Samples 1-4 were the preparation samples of the 3-factor and 2-level orthogonal experiments. It was determined that the $\mathrm{Al}$ powder concentration was $20.0-40.0 \%$, and the silica slurry concentration was $2.0-10.0 \%$. The $\mathrm{Al}$ powder as well as silica slurry was put into the waterborne UV-curable coating, and afterwards $2.0 \% \mathrm{KH} 560$ was added, then mixed and stirred at room temperature for $1 \mathrm{~h}$. Samples 5-11 were an independent test based on the orthogonal test. The fixed silica slurry concentration was $2.0 \%$ and the drying time was $6.0 \mathrm{~min}$, and then $2.0 \% \mathrm{KH} 560$ was added. The concentration of the Al powder was changed.

Table 1. Configuration information of the waterborne UV/Al low infrared emissivity coating.

\begin{tabular}{ccccccccccc}
\hline $\begin{array}{c}\text { Sample } \\
(\#)\end{array}$ & $\begin{array}{c}\text { IPDI } \\
(\mathbf{g})\end{array}$ & $\begin{array}{c}\text { HM } \\
(\mathbf{g})\end{array}$ & $\begin{array}{c}\text { DMPA } \\
(\mathbf{g})\end{array}$ & $\begin{array}{c}\text { TGD } \\
\mathbf{( g )}\end{array}$ & $\begin{array}{c}\text { TBDPO } \\
\mathbf{( g )}\end{array}$ & $\begin{array}{c}\text { PED } \\
\mathbf{( g )}\end{array}$ & $\begin{array}{c}\text { KH560 } \\
(\mathbf{g})\end{array}$ & $\begin{array}{c}\text { Al } \\
\text { Powder } \\
\text { (g) }\end{array}$ & $\begin{array}{c}\text { Nano } \\
\text { Silica } \\
\text { Slurry (g) }\end{array}$ & $\begin{array}{c}\text { Drying } \\
\text { Time } \\
(\mathbf{m i n})\end{array}$ \\
\hline 1 & 26.6 & 22.8 & 4.4 & 7.6 & 3.04 & 11.6 & 2.0 & 20.0 & 2.0 & 2.0 \\
2 & 23.8 & 20.4 & 3.9 & 6.8 & 2.72 & 10.3 & 2.0 & 20.0 & 10.0 & 6.0 \\
3 & 19.6 & 16.8 & 3.2 & 5.6 & 2.24 & 8.5 & 2.0 & 40.0 & 2.0 & 6.0 \\
4 & 16.8 & 14.4 & 2.8 & 4.8 & 1.92 & 7.3 & 2.0 & 40.0 & 10.0 & 2.0 \\
5 & 30.1 & 25.8 & 5.0 & 8.6 & 3.44 & 13.1 & 2.0 & 10.0 & 2.0 & 6.0 \\
6 & 28.3 & 24.3 & 4.7 & 8.1 & 3.24 & 12.3 & 2.0 & 15.0 & 2.0 & 6.0 \\
7 & 26.6 & 22.8 & 4.4 & 7.6 & 3.04 & 11.6 & 2.0 & 20.0 & 2.0 & 6.0 \\
8 & 24.8 & 21.3 & 4.1 & 7.1 & 2.84 & 10.8 & 2.0 & 25.0 & 2.0 & 6.0 \\
9 & 23.1 & 19.8 & 3.8 & 6.6 & 2.64 & 10.0 & 2.0 & 30.0 & 2.0 & 6.0 \\
10 & 21.3 & 18.3 & 3.5 & 6.1 & 2.44 & 9.3 & 2.0 & 35.0 & 2.0 & 6.0 \\
11 & 19.6 & 16.8 & 3.2 & 5.6 & 2.24 & 8.5 & 2.0 & 40.0 & 2.0 & 6.0 \\
\hline
\end{tabular}

First, the substrate was pretreated; that is, sanded, degreased, and dried. The waterborne UV/Al low infrared emissivity coating was applied on the Al substrate by an SZQ tetrahedral fabricator (Beijing Zhongjian road industry instrument and Equipment Co., Ltd., Beijing, China). The coating was dried in a blast dryer (Wujiang Tongfeng Oven Electric Furnace Co., Ltd., Wujiang, China) at 
$40{ }^{\circ} \mathrm{C}$ for $10 \mathrm{~min}$, and afterwards cured by UV radiation of $365 \mathrm{~nm}$ medium pressure mercury lamp $(400 \mathrm{~W})$ in a Fumax 650 UV curing instrument. Radiation curing control and drying curing time control was 2.0-6.0 min. After the coating was cured to a constant weight, the coating was burnished via \#1000 sandpaper, the dust was wiped off using dry cloth, and the aforementioned coating steps were repeated 3 times.

\subsection{Testing and Characterization}

The coating impact resistance was determined using a QCG-50 coating impact tester (Ningbo Yinzhou Rijin testing equipment Co., Ltd., Ningbo, China). The coating of the sample was positioned horizontally on the iron plate, and the weight hammer was fastened on a certain height of the sliding cylinder through the control device. As the control button was pressed, the heavy hammer would fall freely on the press. When lifting the heavy hammer to take out the experimentation plate, the deformation degree of the coating surface was observed, and the height of the heavy hammer falling on the experimentation plate was recorded. Impact resistance referred to the maximum height on the test plate without damaging the coating.

The adhesion was tested according to ISO 2409-2007 [20]. The coating adhesion was determined with a QFH-HG600 coating scriber (Zhongxi Yuanda Technology Co., Ltd., Beijing, China). The handle was held and a multiblade tool was used on the plate. The coating was cut at $20-50 \mathrm{~mm} / \mathrm{s}$ under uniform pressure. Then, the manipulate was repeated by rotating it $90^{\circ}$ to form a $1 \mathrm{~mm} \times 1 \mathrm{~mm}$ grid pattern. The $3 \mathrm{M}$ brand $600-1 \mathrm{PK}$ transparent pressure-sensitive adhesive tape (19 $\mathrm{mm}$ wide) was applied to the entire grid and revealed at a minimum angle. The coating damage was observed. The adhesion level was judged in line with the damage degree. The adhesion of the coating was 0 , which made known that the coating adhesion was the best. Coating hardness was determined via a QHQ-A coating hardness tester (Flora Automation Technology Co., Ltd., Tianjin, China).

Coating gloss was determined with a BGD512-60 gloss meter (3NH Technology Co., Ltd., Shenzhen, China). The color of the coating shall be tested using a SEGT-J colorimeter (Shenyang Guoti Precision Testing Instrument, Liaoning, China). $\mathrm{L}, \mathrm{a}^{*}$ and $\mathrm{b}^{*}$, respectively, stand for the lightness, red-green axis color index and yellow-blue axis color index of the Al plate, while $\mathrm{L}^{\prime}, \mathrm{a}^{* \prime}$ and $\mathrm{b}^{* \prime}$ represent the surface coating of $\mathrm{Al}$ plate. $\Delta \mathrm{L}, \Delta \mathrm{a}^{*}$ and $\Delta \mathrm{b}^{*}$ represent the lightness difference, red-green index difference and yellow-blue index difference of the two samples, respectively. According to the color difference Formula (1), the color difference $\Delta \mathrm{E}$ was computed:

$$
\Delta \mathrm{E}=\left[(\Delta \mathrm{L})^{2}+\left(\Delta \mathrm{a}^{*}\right)^{2}+\left(\Delta \mathrm{b}^{*}\right)^{2}\right]^{1 / 2}
$$

Coating microstructure was characterized with SEM. A Vertex $80 \mathrm{~V}$ infrared spectrometer was used to measure the influence of different $\mathrm{Al}$ powder concentrations on the waterborne UV-curable coating. Far-infrared emissivity of the coating in the range of 8-14 $\mu \mathrm{m}$ was determined using an IR-2 far-infrared emissivity tester (Chinese Academy of Sciences Shanghai Institute of Technological Physics, Shanghai, China). The emissivity measurement instrument uses an active blackbody radiation source to measure the normal reflectivity of the object to be measured, and then measures its normal emissivity in the 8-14 $\mu \mathrm{m}$ infrared band. First, the temperature was set to $250{ }^{\circ} \mathrm{C}$, the power was $43 \%$ and the calibration started after the value was stable. Then the copper reference plate was placed so that the emissivity was 0.45 . The aluminum-coated compensation reference plate was placed on the bracket directly below the test head, and the mirror reflection (MR) was adjusted to make the emissivity reach 0.05 . After adjustment, the infrared emissivity of the coating was tested. The corrosion resistance of the waterborne UV-curable coating was determined by a CHI660E electrochemical workstation (Beijing Jinyang Wanda Technology Co., Ltd., Beijing, China) in line with GB/T 15748-2013 [21], and the $\mathrm{NaCl}$ concentration was $3.5 \%$ at room temperature. A three-electrode cell structure was utilized for the electrochemical experiment. A saturated calomel electrode (SCE) was used as the reference electrode and a platinum electrode as the counter electrode. Each sample was soaked in a 3.5\% $\mathrm{NaCl}$ solution 
and the open circuit potential (OCP) was monitored until constant. The polarization experiment began from scanning with respect to $\mathrm{OCP}-0.3 \mathrm{~V}$ and stopped with respect to $\mathrm{OCP}+0.3 \mathrm{~V}$, and the scanning rate was $10 \mathrm{mV} / \mathrm{s}$. All the experiments were repeated four times with an error of less than $5.0 \%$.

\section{Results and Discussion}

\subsection{Orthogonal Test Analysis of the Al/Waterborne UV-Curable Coating}

According to the range analysis in Table 2 and the influence factors of the orthogonal experiment in Figure 1, compared with the drying time and the concentration of silica slurry, the influence of the Al powder concentration to the gloss was more significant. $k_{1}$ and $k_{2}$ are the average value of the two levels. The interaction between the Al powder concentration and silica slurry is shown in Table 3. When the silica slurry was $10.0 \%$ and Al powder concentration was $20.0 \%$, the gloss was low. The F-test (Table 4) showed that the three factors had no significant effect. Combined with the values of $k_{1}$ and $k_{2}$, the optimal level was as follows: the Al powder concentration was $40.0 \%$, silica slurry concentration was $10.0 \%$ and UV drying time was $6.0 \mathrm{~min}$. It can be seen from the gloss test results that the gloss of Samples 3 and 4 was relatively low, but the silica slurry concentration of Sample 4 was relatively large, considering that the material was more expensive and was not conducive to industrial batches. Based on the above results, it was necessary to conduct further independent experiments on the concentration of the $\mathrm{Al}$ powder. Therefore, in the following independent experiments, the drying time was fixed at $6.0 \mathrm{~min}$, the silica slurry concentration was controlled at $2.0 \%$ and $\mathrm{Al}$ the powder concentration was altered to $10.0 \%, 15.0 \%, 20.0 \%, 25.0 \%, 30.0 \%, 35.0 \%$ and $40.0 \%$. The influences of the $\mathrm{Al}$ powder concentration on the coating properties, such as gloss, infrared emissivity, and color difference, were examined.

Table 2. Orthogonal experiment table for gloss.

\begin{tabular}{ccccc}
\hline Samples (\#) & Al Powder (\%) & Silica Slurry (\%) & UV Curing Time (min) & $\mathbf{6 0}^{\circ}$ Gloss (GU) \\
\hline 1 & 20.0 & 2.0 & 2.0 & 16.0 \\
2 & 20.0 & 10.0 & 6.0 & 13.0 \\
3 & 40.0 & 2.0 & 6.0 & 10.3 \\
4 & 40.0 & 10.0 & 2.0 & 12.3 \\
$\mathrm{k}_{1}$ & 14.5 & 13.15 & 14.15 & \\
$\mathrm{k}_{2}$ & 11.3 & 12.65 & 11.65 & \\
range & 3.2 & 0.5 & 2.5 & \\
\hline
\end{tabular}

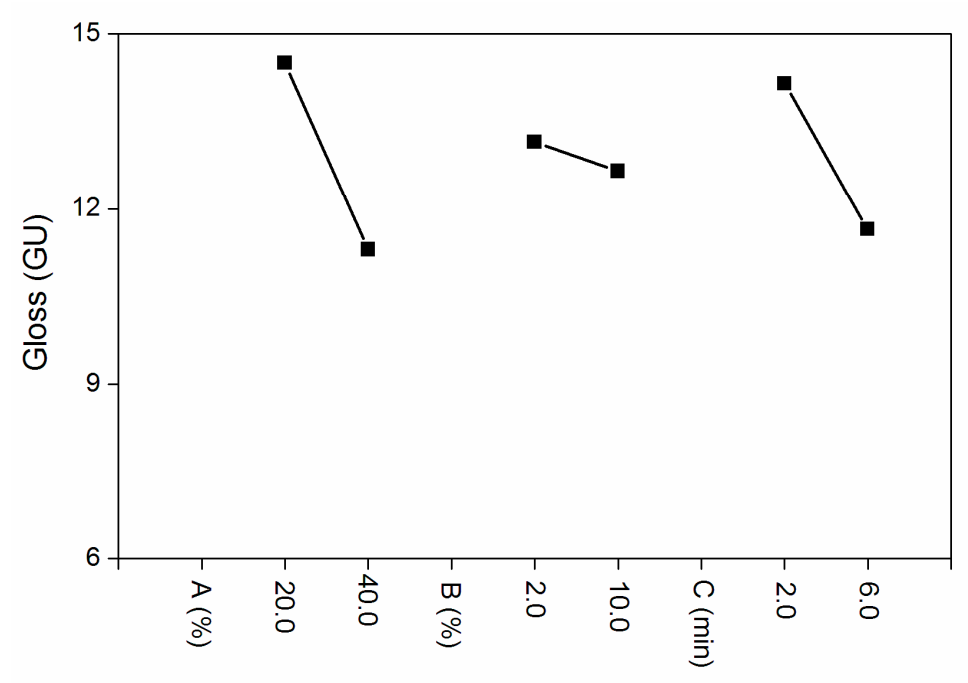

Figure 1. Orthogonal experimental effects of the (A) Al powder, (B) silica slurry concentration and (C) UV drying time. 
Table 3. Interaction table between the silica slurry and $\mathrm{Al}$ powder.

\begin{tabular}{ccc}
\hline \multirow{2}{*}{ Silica Slurry (\%) } & \multicolumn{2}{c}{ Al Powder (\%) } \\
\cline { 2 - 3 } & $\mathbf{2 0 . 0}$ & $\mathbf{4 0 . 0}$ \\
\hline 2.0 & 16.0 & 12.3 \\
10.0 & 10.3 & 13.0 \\
\hline
\end{tabular}

Table 4. F tests.

\begin{tabular}{cccccc}
\hline Factor & $\begin{array}{c}\text { Sum of Squares of } \\
\text { Deviations }\end{array}$ & Freedom & F Ratio & $\begin{array}{c}\text { F Critical } \\
\text { Value }\end{array}$ & Significance \\
\hline Al powder (\%) & 10.240 & 1 & 1.638 & 161.000 & - \\
Silica slurry (\%) & 0.250 & 1 & 0.040 & 161.000 & - \\
$\begin{array}{c}\text { UV drying time } \\
\text { (min) }\end{array}$ & 6.250 & 1 & 1.000 & 161.000 & - \\
\hline
\end{tabular}

\subsection{Influence of the Al Powder Concentration on the Gloss}

The results of the influence of the $\mathrm{Al}$ powder concentration on gloss are exhibited in Figure 2. The trend of the whole gloss showed a " $U$ " pattern. The results show that the gloss lessened at first and then augmented slowly with the augmentation of the Al powder concentration. Figure 2 reflect that when the $\mathrm{Al}$ powder concentration is augmented from $10.0 \%$ to $25.0 \%$, the gloss lessened from 19.1 GU to $8.5 \mathrm{GU}$. As the $\mathrm{Al}$ powder concentration is augmented from $25.0 \%$ to $40.0 \%$, the gloss slowly augmented from $8.5 \mathrm{GU}$ to $10.3 \mathrm{GU}$, and as the concentration of $\mathrm{Al}$ powder exceeded $15.0 \%$, the coating was lusterless. This may be because the augmentation of the concentration of the $\mathrm{Al}$ powder meant that the concentration of the coating lessened, the main coat-forming substances in the coating became less, the reflection of light became smaller and the gloss also lessened [19].

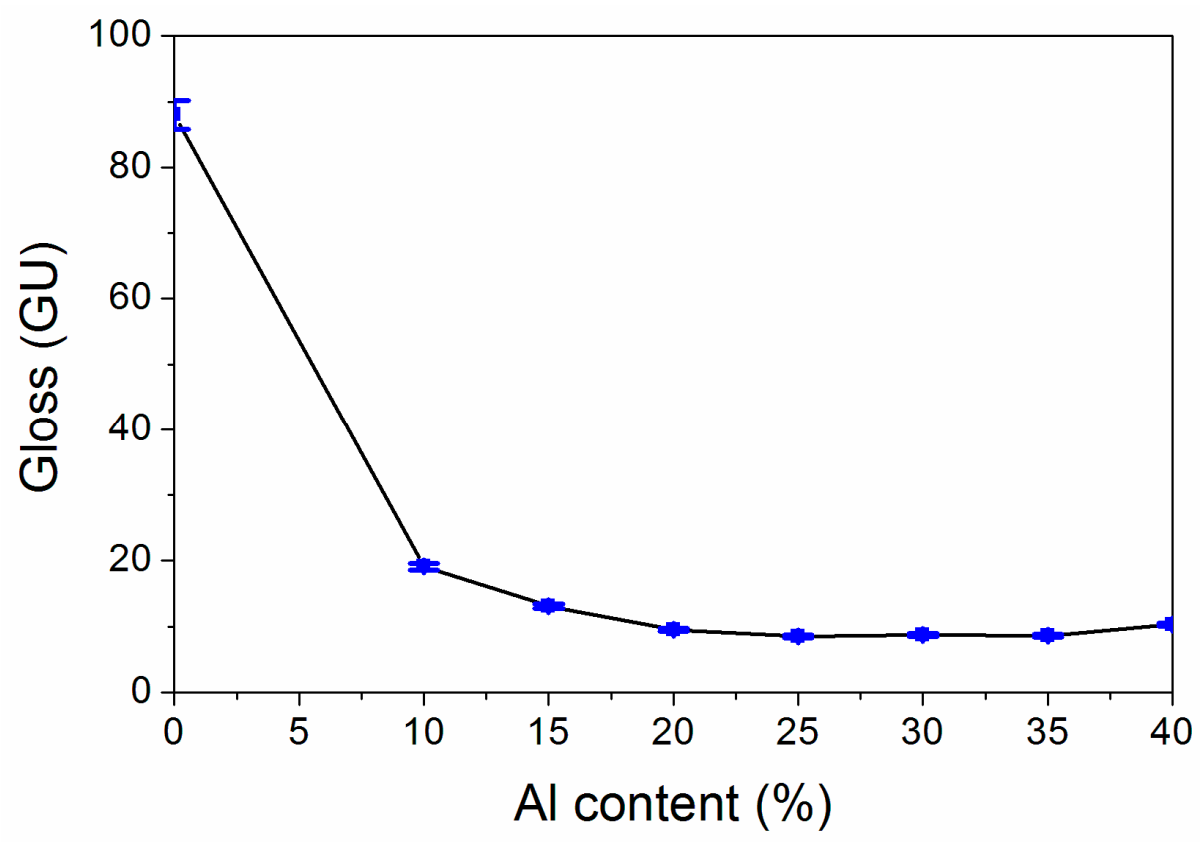

Figure 2. Influence of the $\mathrm{Al}$ powder concentration on gloss.

\subsection{Influence of Al Powder Concentration on Infrared Emissivity}

Emissivity was the main parameter to assess the stealth influence of the coating in the far infrared band. The influence of the Al powder concentration on infrared emissivity is exhibited in Figure 3, from which we can find that the infrared emissivity value of the coating lessened gradually with the $\mathrm{Al}$ 
powder concentration increasing. As the $\mathrm{Al}$ powder concentration is augmented from $10.0 \%$ to $40.0 \%$, the coating infrared emissivity lessened from 0.649 to 0.083 . As the Al powder concentration was $35.0 \%$, the infrared emissivity was 0.128 , which was also very low. This was because the augmentation of the $\mathrm{Al}$ powder concentration could enhance the reflection of the visible light from the coating, thus weakening the reflection of the invisible light and reducing the infrared emissivity [22].

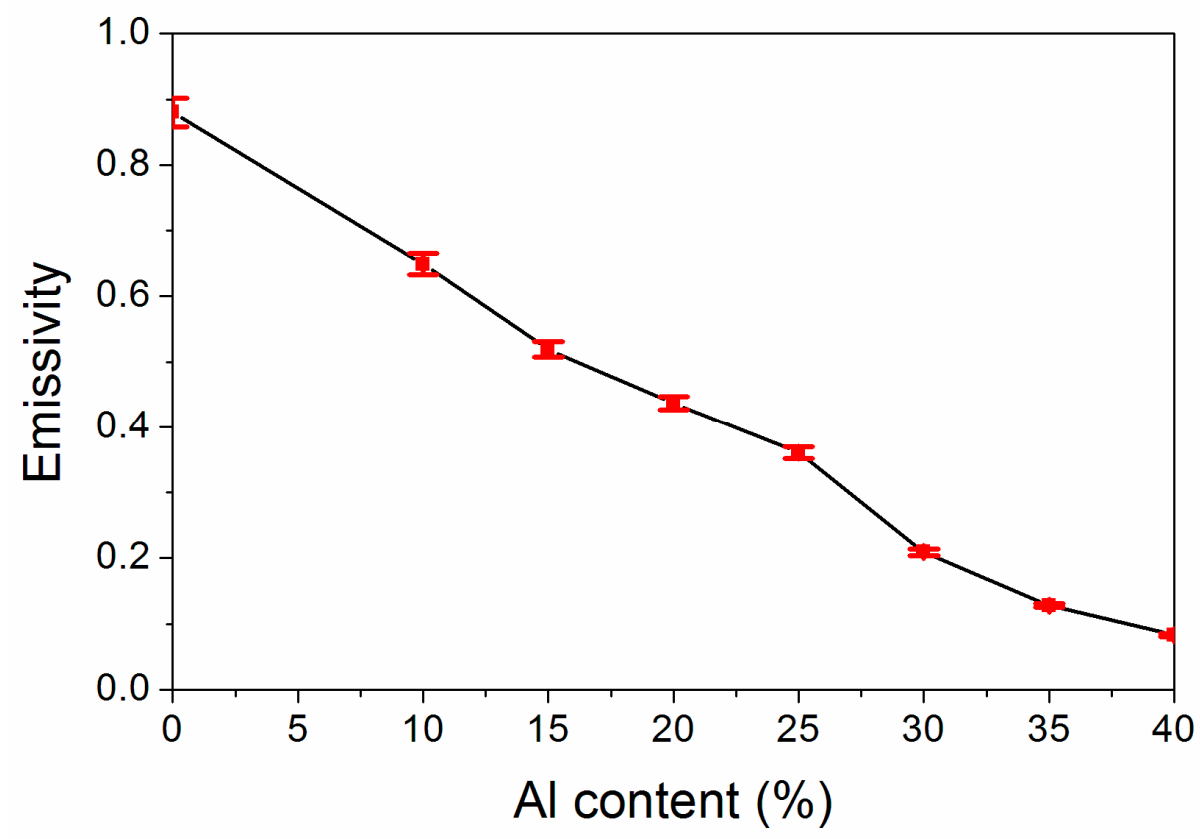

Figure 3. Influence of Al powder concentration on the coating's infrared emissivity.

\subsection{Influence of Al Powder Concentration on Color Difference}

Chromaticity refer to the color value when a multi-color light was used as the light source. In the visible light band, color was the main characteristic parameter of its visible light stealth ability. The L' in Table 5 represented the brightness of the waterborne UV-curable coating, indicating the reflection degree of the object to the incident light on its surface. The higher the $L^{\prime}$, the whiter the object and the higher the brightness. Along with the augmented Al powder concentration, the lightness $\mathrm{L}^{\prime}$ value was gradually augmented and stabilized. As the $\mathrm{Al}$ powder concentration was augmented from $10.0 \%$ to $30.0 \%$, the lightness $L^{\prime}$ value of the coating was augmented from 65.8 to 75.2 , while when the Al powder concentration was augmented from $30.0 \%$ to $40.0 \%$, the lightness $\mathrm{L}^{\prime}$ value of the coating was only augmented from 75.2 to 76.8 , with a small change in lightness. The reason was that the gloss was augmented with the augmentation of the sheet metal Al powder concentration, which lead to the augmentation of the luminosity L' value of the coating. A low infrared emissivity coating needs to reduce the brightness value of the coating for the sake of reducing the detection of infrared detection equipment, so the darker coating was better. According to Table 5, the coating with a low Al powder concentration had a lower brightness. 
Table 5. Influence of the $\mathrm{Al}$ powder concentration on the L' value of the coating.

\begin{tabular}{|c|c|c|c|c|c|c|c|c|c|c|}
\hline $\begin{array}{l}\text { Al Powder } \\
\text { Concentration } \\
\quad(\%)\end{array}$ & $\mathbf{L}$ & $a^{*}$ & $\mathbf{b}^{*}$ & $\mathbf{L}^{\prime}$ & $a^{* \prime}$ & $b^{* \prime}$ & $\Delta \mathrm{L}$ & $\Delta a^{*}$ & $\Delta \mathrm{b}^{*}$ & $\Delta \mathrm{E}$ \\
\hline 0 & $25.9 \pm 0.3$ & $5.2 \pm 0.1$ & $-3.1 \pm 0.2$ & $37.6 \pm 0.5$ & $6.9 \pm 0.2$ & $-12.1 \pm 0.4$ & $11.7 \pm 0.2$ & $1.7 \pm 0.0$ & $-9.0 \pm 0.2$ & $14.9 \pm 0.2$ \\
\hline 15.0 & $25.9 \pm 0.3$ & $5.2 \pm 0.1$ & $-3.1 \pm 0.2$ & $69.1 \pm 0.4$ & $1.8 \pm 0$ & $-2.7 \pm 0$ & $43.2 \pm 0.5$ & $-3.4 \pm 0.2$ & $0.4 \pm 0$ & $43.3 \pm 0.9$ \\
\hline 20.0 & $25.9 \pm 0.3$ & $5.2 \pm 0.1$ & $-3.1 \pm 0.2$ & $71.9 \pm 0.5$ & $2.0 \pm 0$ & $-3.7 \pm 0$ & $46.0 \pm 1.9$ & $-3.2 \pm 0.2$ & $-0.6 \pm 0$ & $46.1 \pm 0$ \\
\hline 25.0 & $25.9 \pm 0.3$ & $5.2 \pm 0.1$ & $-3.1 \pm 0.2$ & $74.7 \pm 0.5$ & $2.3 \pm 0$ & $-3.9 \pm 0$ & $48.8 \pm 0.3$ & $-2.9 \pm 0.2$ & $-0.8 \pm 0$ & $48.9 \pm 0.3$ \\
\hline 40.0 & $25.9 \pm 0.3$ & $5.2 \pm 0.1$ & $-3.1 \pm 0.2$ & $76.8 \pm 0.6$ & $3.2 \pm 0$ & $-5.8 \pm 0.1$ & $50.9 \pm 1.2$ & $-2.0 \pm 0.1$ & $-2.7 \pm 0$ & $51.0 \pm 1.4$ \\
\hline
\end{tabular}

\subsection{Influence of Al Powder Concentration on Mechanical Properties}

The mechanical properties of the waterborne UV/Al coating with a low infrared emissivity were excellent. As the concentration was $10.0-40.0 \%$, the coating hardness was $6 \mathrm{H}$ (Table 6). This may be due to the high degree of crosslinking of the UV-curable coatings [23]. When the concentration of the Al powder was increasing, the adhesion was good, and the level was 0 . This was because the Al powder can be well distributed in the coating with the no agglomeration. The impact resistance can reflect the flexibility and rigidity of the coating. The experimental data exhibited that, as the concentration was 10.0-40.0\%, the impact resistance was better, which was greater than $50.0 \mathrm{~kg} \mathrm{~cm}$. This showed that good adhesion provided strong support for the coating with high impact resistance.

Table 6. Effect of the Al powder concentration on hardness, adhesion and impact resistance.

\begin{tabular}{cccc}
\hline Al Powder Concentration (\%) & Hardness & Adhesion (level) & Impact Resistance (kg cm) \\
\hline 0 & $\mathrm{H} \pm 0$ & $3 \pm 0$ & $25.00 \pm 0.02$ \\
10.0 & $6 \mathrm{H} \pm 0$ & $0 \pm 0$ & $50.00 \pm 0.20$ \\
15.0 & $6 \mathrm{H} \pm 0$ & $0 \pm 0$ & $50.00 \pm 0.20$ \\
20.0 & $6 \mathrm{H} \pm 0$ & $0 \pm 0$ & $50.00 \pm 0.10$ \\
25.0 & $6 \mathrm{H} \pm 0$ & $0 \pm 0$ & $50.00 \pm 0.40$ \\
30.0 & $6 \mathrm{H} \pm 0$ & $0 \pm 0$ & $50.00 \pm 0.36$ \\
35.0 & $6 \mathrm{H} \pm 0$ & $0 \pm 0$ & $50.00 \pm 0.30$ \\
40.0 & $6 \mathrm{H} \pm 0$ & $0 \pm 0$ & $50.00 \pm 0.28$ \\
\hline
\end{tabular}

\subsection{Chemical Composition of the Waterborne UV/Al Low Infrared Emissivity Coating}

According to Figure 4 and Table 7, the wavenumber of $3343 \mathrm{~cm}^{-1}$ was an $-\mathrm{OH}$ stretching vibration [24]. A wavenumber of $1724 \mathrm{~cm}^{-1}$ was the characteristic absorption peak of $C=O$ [25], while wavenumber $1530 \mathrm{~cm}^{-1}$ was the $\mathrm{N}-\mathrm{H}$ bending vibration of the amide II band [26], indicating that there were a large number of carbamate bonds in the product. At wavenumber $1670 \mathrm{~cm}^{-1}$, the characteristic absorption peak of the $\mathrm{C}=\mathrm{C}$ double bond could appear [27]. Moreover, the characteristic absorption peaks of $-\mathrm{CH}$ were $2930 \mathrm{~cm}^{-1}$ and $1462 \mathrm{~cm}^{-1}$ [28], and the C-O located at $1049 \mathrm{~cm}^{-1}$ and $1120 \mathrm{~cm}^{-1}$ [29]. In addition, the $\mathrm{N}-\mathrm{C}-\mathrm{O}$ stretching vibration at $1256 \mathrm{~cm}^{-1}$ was found too [30]. According to the intensity of the wave peak, at the $40.0 \%$ concentration, the wave peak of the infrared spectrum was basically the same, which had a high reflectivity to the infrared, so it was more instrumental in reducing the coating surface emissivity. 


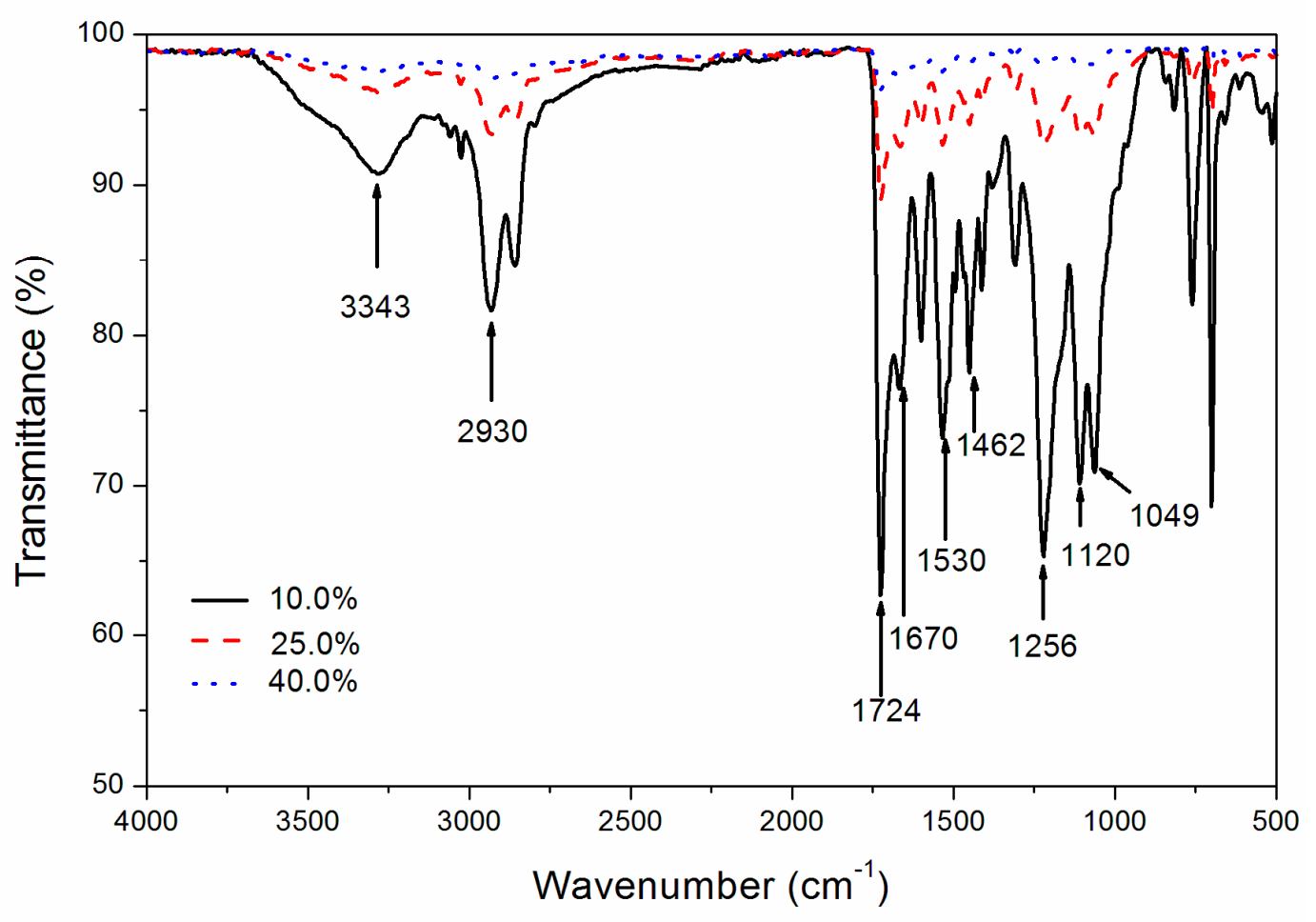

Figure 4. Influence of the $\mathrm{Al}$ powder concentration on the infrared spectrum.

Table 7. Assignment of the bands.

\begin{tabular}{cc}
\hline Band $\left.\mathbf{( c m}^{-\mathbf{1}}\right)$ & Assignment \\
\hline 3343 & $-\mathrm{OH}$ stretching vibration \\
1724 & $\mathrm{C}=\mathrm{O}$ absorption \\
1530 & $\mathrm{~N}-\mathrm{H}$ bending vibration of the amide II band \\
1670 & $\mathrm{C}=\mathrm{C}$ absorption \\
2930,1642 & $-\mathrm{CH}$ absorption \\
1049,1120 & $\mathrm{C}-\mathrm{O}$ absorption \\
1256 & $\mathrm{~N}-\mathrm{C}-\mathrm{O}$ stretching vibration \\
\hline
\end{tabular}

\subsection{Chemical Composition of the Waterborne UV/Al Low Infrared Emissivity Coating}

After the infrared emissivity, lightness, mechanical properties and infrared spectrum tests, it was found that the comprehensive properties of samples with the $20.0-30.0 \% \mathrm{Al}$ powder were better. Therefore, the electrochemical polarization curve in Figure 5 was obtained after the corrosion resistance test of coating with a concentration of $20.0-30.0 \%$. The main electrochemical parameters of Figure 5 were acquired from the Tafel polarization curves in Table $8 . R_{P}$ is the polarization resistance of the coated substrate; $\mathrm{E}_{\text {corr }}$ is the corrosion potential of the coating, $\mathrm{I}_{\mathrm{corr}}$ is the corrosion current density; and $\beta_{\mathrm{a}}$ and $\beta_{\mathrm{c}}$ are the anode constant and cathode constant, respectively. The corrosion resistance was positively correlated with the potential $\mathrm{E}_{\mathrm{corr}}(\mathrm{V})$. The corrosion resistance of the waterborne UV coating at $25.0 \% \mathrm{Al}$ powder was the best. 


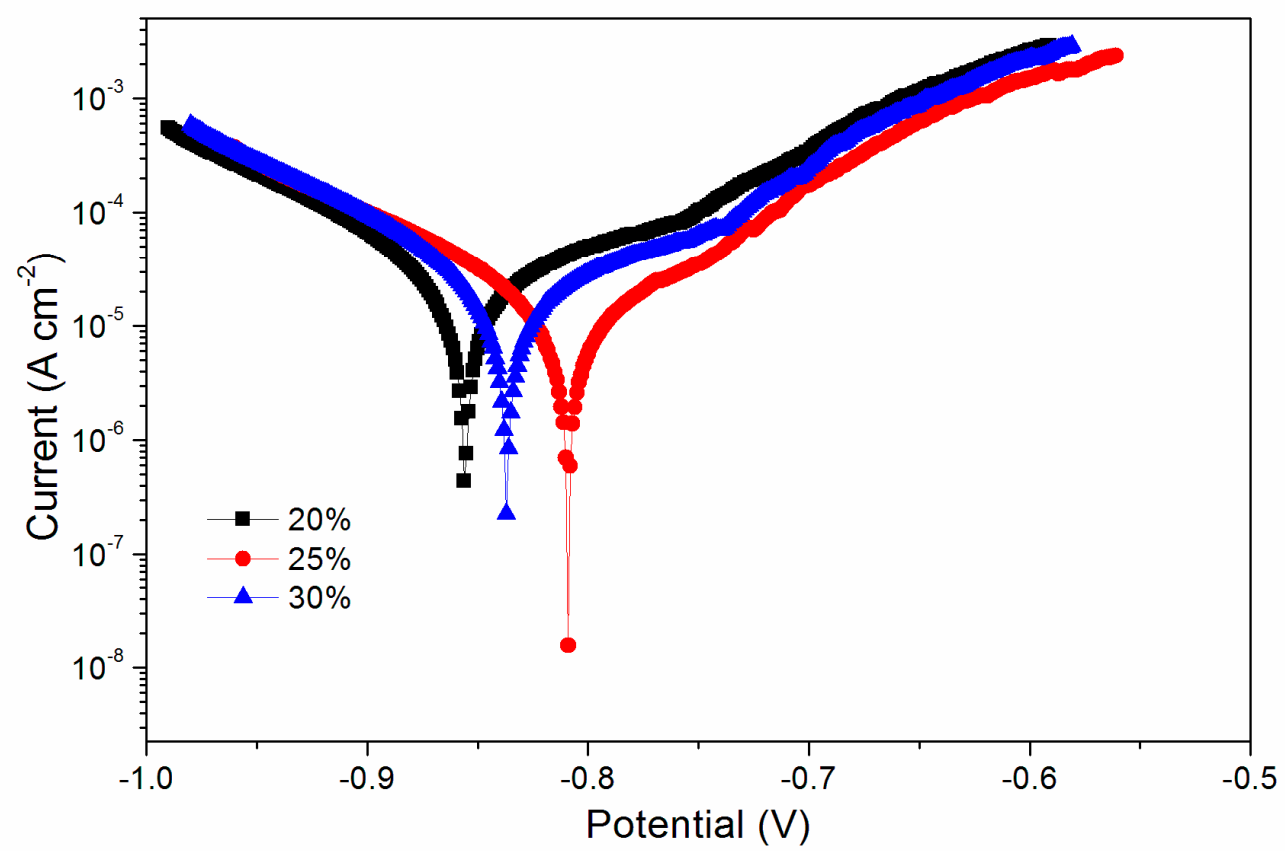

Figure 5. Electrochemical curve of the coating with an $\mathrm{Al}$ powder concentration of $20.0 \%, 25.0 \%$ and $30.0 \%$.

Table 8. Influence of the Al powder concentration on corrosion resistance.

\begin{tabular}{cccccc}
\hline Al Powder Concentration $\mathbf{( \% )}$ & $\mathbf{E}_{\text {corr }}(\mathbf{V})$ & $\mathbf{R}_{\mathbf{p}}\left(\boldsymbol{\Omega} / \mathbf{c m}^{\mathbf{2}}\right)$ & $\mathbf{I}_{\text {corr }}\left(\mathbf{A} / \mathbf{c m}^{\mathbf{2}}\right)$ & $\boldsymbol{\beta}_{\mathbf{a}}(\mathbf{m V} / \mathbf{d e c})$ & $\boldsymbol{\beta}_{\mathbf{c}}(\mathbf{m V} / \mathbf{d e c})$ \\
\hline 20.0 & -0.856 & 883.6 & $2.992 \times 10^{-5}$ & 139.0 & 108.0 \\
25.0 & -0.809 & 1534.4 & $1.250 \times 10^{-5}$ & 70.8 & 117.0 \\
30.0 & -0.837 & 1026.2 & $2.276 \times 10^{-5}$ & 107.0 & 108.0 \\
\hline
\end{tabular}

\subsection{Surface Morphology of Waterborne UV/Al Coatings with Low Infrared Emissivity}

From the SEM in Figure 6, it can be seen that the continuous and dense flake Al powder structure with a good spreading property was formed on different coating surfaces, and the morphology of the three was not different. However, compared with other Al powders, when the concentration of the $\mathrm{Al}$ powder was $25.0 \%$, there was no gap on the surface of the coating, the distribution of the flake Al was more uniform and the coating performance was better.
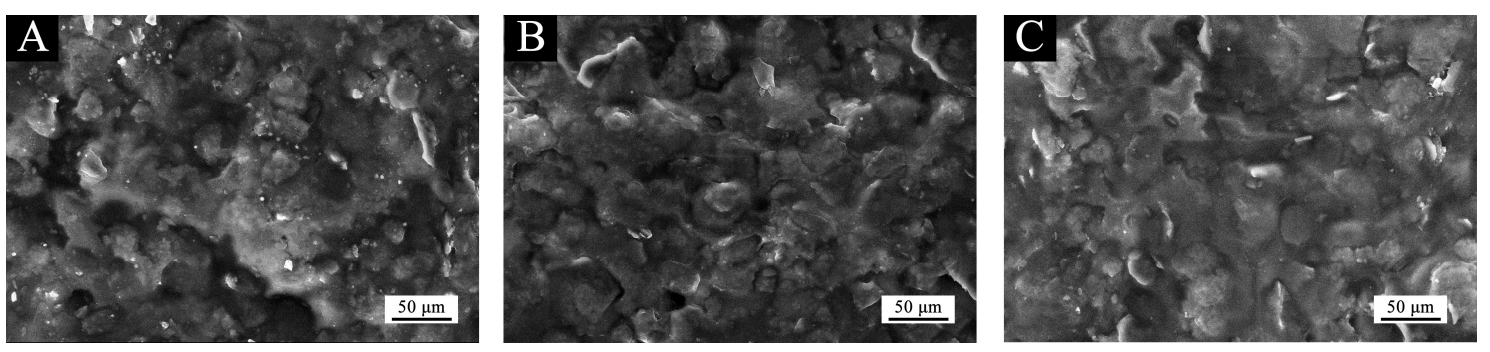

Figure 6. SEM of coating with Al powder: (A) 20.0\%, (B) $25.0 \%$ and (C) $30.0 \%$.

The performance of the waterborne UV/Al coating was compared with those of epoxy-lacquer-based coatings [31], PU-based coatings [32-34] and waterborne acrylic-based coatings [16], as shown in Table 9. Compared with other coatings, the infrared emissivity of the waterborne UV/Al coating was slightly higher than other coatings with a value of 0.361 . The gloss of the waterborne UV/Al coating was lower than that of the PU-based coatings, which was like that of the epoxy-lacquer-based coatings and $\mathrm{Al} /$ waterborne acrylic coating. The adhesion of the waterborne $\mathrm{UV} / \mathrm{Al}$ coating was as high as the $\mathrm{Al} /$ waterborne acrylic coating, which was at level 0 . The impact 
resistance of the waterborne UV/Al coating was the largest, which exceeded $50.0 \mathrm{~kg} \mathrm{~cm}$. The impact resistance of the waterborne UV/Al coating was better than the other coatings.

Table 9. Performance comparison of the waterborne UV-based coating with epoxy-lacquer-based coatings, PU-based coatings and waterborne acrylic-based coatings.

\begin{tabular}{cccccc}
\hline Coating & $\begin{array}{c}\text { Filler } \\
\text { Concentration (\%) }\end{array}$ & Emissivity & Gloss (GU) & $\begin{array}{c}\text { Adhesion } \\
\text { (level) }\end{array}$ & $\begin{array}{c}\text { Impact Resistance } \\
\text { (kg cm) }\end{array}$ \\
\hline $\begin{array}{c}\text { Epoxy-lacquer/Al } \\
\text { PU/Cu }\end{array}$ & 30.0 & 0.065 & 5.7 & 1 & 50.0 \\
PU/(ball-milled & 50.0 & 0.100 & 45.2 & 3 & 20.0 \\
Ag-Cu) & 50.0 & 0.129 & 35.6 & 3 & 20.0 \\
$\begin{array}{c}\text { PU/Al } \\
\text { Al/waterborne }\end{array}$ & 40.0 & 0.068 & 38.3 & 1 & 40.0 \\
$\begin{array}{c}\text { acrylic coating } \\
\text { Waterborne } \\
\text { UV/Al }\end{array}$ & 30.0 & 0.113 & 7.7 & 0 & 50.0 \\
\hline
\end{tabular}

\section{Conclusions}

Among the three factors, the most significant one was the concentration of the Al powder. By changing the concentration of the $\mathrm{Al}$ powder, the influence of the $\mathrm{Al}$ powder on the infrared emissivity, gloss, color difference, hardness, corrosion resistance as well as other properties of the waterborne UV-curable coating was studied. The optimal concentration of the Al powder was explored when the original good performance was ensured, and the low infrared emissivity, low sub light and low brightness values were simultaneously possessed. The results demonstrated that at the $25.0 \% \mathrm{Al}$ powder concentration, the hardness, adhesion, impact resistance and corrosion resistance of the waterborne UV-curable coating were higher; the infrared emissivity and gloss were also lower. Conclusively, it is acknowledged that the value of the paper lies in the methodology adopted to fabricate waterborne UV/Al low infrared emissivity coatings.

Author Contributions: Conceptualization, X.Y.; Methodology, X.Y.; Validation, X.Y.; Resources, X.Y.; Data Curation, X.Y.; Writing-Original Draft Preparation, X.Y.; Supervision, X.Y.; Data Analysis, L.W.; Investigation, L.W.; Writing - Review and Editing, L.W. All authors have read and agreed to the published version of the manuscript.

Funding: This research was funded by the General Program of Jiangsu Natural Science Foundation in 2020 (Project title: Study on the relationship between microstructure control of self repairing coating and wood based on microcapsule technology) and the Youth Science and Technology Innovation Fund of Nanjing Forestry University, Grant Number (CX2016018).

Conflicts of Interest: The authors declare no conflict of interest.

\section{References}

1. Dong, H.L.; Wang, J.C.; Zeng, Y.R.; Chen, Z.S.; Shi, J.M. Reflection spectrum study of THz wave by infrared low emissivity stealth coating. Spectrosc. Spect. Anal. 2019, 39, 3007-3012.

2. Li, Q.Y.; Cheng, X.D.; Gong, D.Q.; Ye, W.P. Effect of $\mathrm{N}_{2}$ flow rate on structural and infrared properties of multi-layer $\mathrm{AlCrN} / \mathrm{Cr} / \mathrm{AlCrN}$ coatings deposited by cathodic arc ion plating for low emissivity applications. Thin Solid Films 2019, 675, 74-85. [CrossRef]

3. Lv, D.D.; Fang, N.; Zhang, W.G. A PDMS modified polyurethane/Ag composite coating with super-hydrophobicity and low infrared emissivity. Infrared Phys. Technol. 2020, 108, 103351. [CrossRef]

4. He, L.H.; Zhao, Y.; Xing, L.Y.; Liu, P.G.; Zhang, Y.W.; Wang, Z.Y. Low infrared emissivity coating based on graphene surface-modified flaky aluminum. Materials 2018, 11, 1502. [CrossRef] [PubMed]

5. Voti, R.L.; Larciprete, M.C.; Leahu, G.; Sibilia, C.; Bertolotti, M. Optimization of thermochromic $\mathrm{VO}_{2}$ based structures with tunable thermal emissivity. J. Appl. Phys. 2012, 112, 034305. [CrossRef]

6. Yang, F.; Wu, Y.; Zhang, S.Q.; Zhang, H.M.; Zhao, S.L.; Zhang, J.L.; Fei, B.H. Mechanical and thermal properties of waterborne polyurethane coating modified through one-step cellulose nanocrystals/graphene materials sols method. Coatings 2020, 10, 40. [CrossRef] 
7. Wu, Y.; Wu, J.M.; Wang, S.Q.; Feng, X.H.; Chen, H.; Tang, Q.W.; Zhang, H.Q. Measurement of mechanical properties of multilayer waterborne coatings on wood by nanoindentation. Holzforschung 2019, 73, 871-877. [CrossRef]

8. Aizpurua, J.; Martin, L.; Fernandez, M.; Gonzalez, A.; Irusta, L. Recyclable, remendable and healing polyurethane/acrylic coatings from UV curable waterborne dispersions containing Diels-Alder moieties. Prog. Org. Coat. 2020, 139, 105460. [CrossRef]

9. Wu, Y.; Wu, X.Y.; Yang, F.; Ye, J.Y. Preparation and characterization of waterborne UV lacquer product modified by zinc oxide with flower shape. Polymers 2020, 12, 668. [CrossRef]

10. Chen, J.H.; Yuan, T.; Tu, W.P.; Peng, K.M.; Hu, J.Q.; Wang, F. Electrophoretic deposition of waterborne ultraviolet (UV)-curable coatings based on microgels. J. Coat. Technol. Res. 2019, 16, 1367-1378. [CrossRef]

11. Hwang, H.D.; Moon, J.I.; Choi, J.H.; Kim, H.J.; Do Kim, S.; Park, J.C. Effect of water drying conditions on the surface property and morphology of waterborne UV-curable coatings for engineered flooring. J. Ind. Eng. Chem. 2009, 15, 381-387. [CrossRef]

12. Zhao, J.; Luo, W.; Qi, L.; Yuan, L.; Huang, G.; Huang, Y.; Weng, X.L. The high-temperature resistance properties of polysiloxane/Al coatings with low infrared emissivity. Coatings 2018, 8, 125. [CrossRef]

13. Qi, L.; Weng, X.L.; Wei, B.; Yuan, L.; Huang, G.; Du, X.B.; Wu, X.Y.; Liu, H.X. Effects of low-melting glass powder on the thermal stabilities of low infrared emissivity Al/polysiloxane coatings. Prog. Org. Coat. 2020, 142, 105579. [CrossRef]

14. Zhang, W.G.; Jiang, S.N.; Lv, D.D. Fabrication and characterization of a PDMS modified polyurethane/Al composite coating with super-hydrophobicity and low infrared emissivity. Prog. Org. Coat. 2020, 143, 105622. [CrossRef]

15. Hu, C.; Xu, G.Y.; Shen, X.M.; Shao, C.M.; Yan, X.X. The epoxy-siloxane/Al composite coatings with low infrared emissivity for high temperature applications. Appl. Surf. Sci. 2010, 256, 3459-3463. [CrossRef]

16. Yan, X.X.; Wang, L.; Qian, X.Y. Preparation and characterization of low infrared emissive aluminum/waterborne acrylic coatings. Coatings 2020, 10, 35. [CrossRef]

17. Liu, Q.Q.; Gao, D.; Xu, W. Effect of sanding processes on the surface properties of modified Poplar coated by primer compared with Mahogany. Coatings 2020, 10, 856.

18. Xia, Y.Q.; He, Y.; Chen, C.L.; Wu, Y.Q.; Zhong, F.; Chen, J.Y. Co-modification of polydopamine and KH560 on g-C3N4 nanosheets for enhancing the corrosion protection property of waterborne epoxy coating. React. Funct. Polym. 2020, 146, 104405. [CrossRef]

19. Sow, C.; Riedl, B.; Blanchet, P. UV-waterborne polyurethane-acrylate nanocomposite coatings containing alumina and silica nanoparticles for wood: Mechanical, optical, and thermal properties assessment. J. Coat. Technol. Res. 2011, 8, 211-221. [CrossRef]

20. International Organization for Standardization. ISO 2409-2007 Paints and Varnishes-Cross-Cut Test; International Organization for Standardization: Geneva, The Switzerland, 2007.

21. Standardization Administration of the People's Republic of China. GB/T15748-2013 The Method of Galvanic Corrosion Test for Metallic Ship Materials; Standardization Administration of the People's Republic of China: Beijing, China, 2013; pp. 1-4. (In Chinese)

22. Yuan, L.; Hu, J.; Weng, X.L.; Zhang, Q.Y.; Deng, L.J. Galvanic displacement synthesis of Al/Ni core-shell pigments and their low infrared emissivity application. J. Alloy. Compd. 2016, 670, 275-280. [CrossRef]

23. Liang, B.; Li, R.P.; Zhang, C.Q.; Yang, Z.H.; Yuan, T. Synthesis and characterization of a novel tri-functional bio-based methacrylate prepolymer from castor oil and its application in UV-curable coatings. Ind. Crop. Prod. 2019, 135, 170-178. [CrossRef]

24. Sahlberg, A.L.; Hot, D.; Lyngbye-Pedersen, R.; Zhou, J.F.; Alden, M.; Li, Z.S. Mid-infrared polarization spectroscopy measurements of species concentrations and temperature in a low-pressure flame. Appl. Spectrosc. 2019, 73, 653-664. [CrossRef]

25. Xu, H.P.; Qiu, F.X.; Wang, Y.Y.; Wu, W.L.; Yang, D.Y.; Guo, Q. UV-curable waterborne polyurethane-acrylate: Preparation, characterization and properties. Prog. Org. Coat. 2012, 73, 47-53. [CrossRef]

26. Feng, C.G.; Bai, L.S.; Rein, Q.S. Preparation and FTIR properties of amino compounds modified glutaraldehyde crosslinked chitosan resin activated with cyanuric chloride. Spectrosc. Spect. Anal. 2004, 24, 1315-1318.

27. Kwag, G. A highly reactive and monomeric neodymium catalyst. Macromolecules 2002, 35, 4875-4879. [CrossRef] 
28. Sun, D.W.; Zhang, H.; Tang, X.Z.; Yang, J.L. Water resistant reactive microcapsules for self-healing coatings in harsh environments. Polymer 2016, 91, 33-40. [CrossRef]

29. Habuka, A.; Yamada, T.; Nakashima, S. Interactions of glycerol, diglycerol, and water studied using attenuated total reflection infrared spectroscopy. Appl. Spectrosc. 2020, 74, 767-779. [CrossRef]

30. Chen, H.; Yu, X.L.; Zhou, W.Y.; Peng, S.X.; Zhao, X.P. Highly toughened polylactide (PLA) by reactive blending with novel polycaprolactone-based polyurethane (PCLU) blends. Polym. Test. 2018, 70, 275-280. [CrossRef]

31. Yan, X.X.; Cai, Y.T.; Lu, R.; Miyakoshi, T. Development and characterization of new coating material of blended epoxy-lacquer with aluminum. Int. J. Polym. Sci. 2017, 2017, 5017356. [CrossRef]

32. Yan, X.X.; Xu, G.Y. Effect of surface modification of $\mathrm{Cu}$ with $\mathrm{Ag}$ by ball-milling on the corrosion resistance of low infrared emissivity coating. Mater. Sci. Eng. B Adv. 2010, 166, 152-157. [CrossRef]

33. Yan, X.X.; Xu, G.Y. Influence of silane coupling agent on corrosion-resistant property in low infrared emissivity $\mathrm{Cu}$ /polyurethane coating. Prog. Org. Coat. 2012, 73, 232-238. [CrossRef]

34. Yan, X.X.; Xu, G.Y. Corrosion and mechanical properties of polyurethane/Al composite coatings with low infrared emissivity. J. Alloys Compd. 2010, 491, 649-653. [CrossRef]

(C) 2020 by the authors. Licensee MDPI, Basel, Switzerland. This article is an open access article distributed under the terms and conditions of the Creative Commons Attribution (CC BY) license (http://creativecommons.org/licenses/by/4.0/). 